\title{
LA VIDA ES SUEÑO \\ LEÍDA DESDE EL DESENLACE
}

\author{
Christophe Couderc \\ UFR d'Études Ibériques et Latino-Américaines \\ Université de Paris IV, Paris-Sorbonne \\ 31 rue Gay-Lussac \\ 75005 Paris. France \\ christophe.couderc@paris4.sorbonne.fr
}

[Anuario calderoniano (ISSN: 1888-8046), 4, 2011, pp. 79-97]

Dejando de lado las interpretaciones de tipo filosófico o moral de La vida es sueño, que han sido con razón numerosas y variadas, en este trabajo pretendemos interesarnos por la construcción de su acción, por sus estructuras. Considerar una pieza de teatro desde el punto de vista formal, con la atención puesta en el desarrollo de la acción a partir de su punto de partida y hasta su desenlace significa ante todo aprehenderla como obra de arte dramático y como el resultado de un proceso de producción; significa tomar en cuenta la génesis de dicha obra, la temporalidad de su creación, no necesariamente con la ambición de reconstruir perfectamente y en todas sus fases el proceso de elaboración de dicha comedia, pero de alguna forma sí con la ambición de situarse en el taller del poeta que la compuso. 
Como veremos, una de las problemáticas subyacentes, o inferidas, por este tipo de acercamiento dramatúrgico a una obra de teatro tiene que ver con la cuestión muy espinosa del género: ¿a qué género, o mejor dicho a qué subgénero, en el complejo panorama de la taxonomía del teatro áureo, pertenece La vida es sueño? La definición de un género o de un subgénero supone la determinación de una serie de rasgos formales o estructurales sin los cuales no puede darse esta definición. Pero la reflexión taxonómica no es solamente una cuestión teórica y general con miras a proponer unos principios de clasificación del conjunto del repertorio teatral, sino que se plantea en cualquier lectura atenta de una obra determinada, ya que una comedia siempre es un ejemplar de una categoría, subcategoría o subespecie, hecho complicado además con la dificil cronología del teatro áureo. En efecto, muchas veces estamos condenados a hipótesis acerca de posibles efectos de la emulación entonces vigente entre distintos poetas que buscaban la aprobación del público, creándose así fenómenos de moda que la incierta datación de muchas comedias no permiten describir como nos gustaría. Todo ello supondría, en el mejor de los casos, que el enfoque puesto en una pieza particular fuera siempre contrastivo y comparativo con otras obras coetáneas.

Desde esta perspectiva, uno diría que tiene la sensación, frente a La vida es sueño, de estar ante una obra atípica y quizás experimental, en la que un dramaturgo aún joven combina modelos genéricos dispares como si se lanzara a sí mismo un reto artístico y como si estuviera tanteando en busca de una propuesta genérica original. Si además se toma en cuenta el argumento ecdótico defendido por Ruano de la Haza y otros críticos, según quienes La vida es sueño hubiera sido escrita en $1628^{1}$, es verosímil considerar que Calderón haya querido hacer alarde de su habilidad de dramaturgo, de sus dotes para manejar y renovar las convenciones al uso cuando se trataba de escribir una comedia en los umbrales de los años treinta, tan fértiles en renovaciones estéticas de todo tipo.

${ }^{1}$ Ruano de la Haza, 1992. 


\section{LA INTRIGA SECUNDARIA}

Uno de los aspectos más notables de la construcción de la acción de La vida es sueño, y que por lo tanto ha despertado la atención de la crítica, es la presencia de una intriga secundaria, es decir, de un hilo narrativo, de una parte de la fábula o del muthos (según el léxico de Aristóteles) hasta cierto punto independiente de la trama que se construye en torno al protagonista de la obra. Rosaura, heroína de esta trama secundaria, llega a Polonia disfrazada de hombre y movida por la voluntad de restaurar su honor después de haber sido seducida y abandonada por Astolfo, gran duque de Moscovia. Perdida en el monte hostil, llega a la torre donde Segismundo vive apartado del mundo de los hombres, y merced a esa casualidad se lanza la acción dramática con el encuentro de dos personajes de identidad dudosa, por lo menos en el plano superficial de su apariencia fisica (una mujer-hombre y un hombre-bruto). La historia de Rosaura tiene su propia coherencia, el personaje tiene sus propios objetivos, que hacen su trayectoria individual distinta de la de Segismundo, héroe indiscutible de la pieza. Príncipe heredero de la corona polaca, es en efecto éste quien suscita continuamente el interés del espectador, con su intento de recuperación del trono que le pertenece por derecho natural. La historia de Segismundo sigue principalmente una trama política, involucra a personajes de alta categoría social, ilustres y más o menos históricos, en un conflicto de gran alcance, ya que el nudo de la intriga es nada menos que una sucesión en el trono; la acción se desarrolla en el palacio, lugar del poder político, o en el campo de batalla, marco de hazañas y de gestos heroicos. En esta trama principal de La vida es sueño, las acciones tienen consecuencias políticas (colectivas) porque sus sujetos, nobles y heroicos, no sólo son movidos por las pasiones, sino que obedecen a la razón y buscan la virtud, aunque eso signifique (porque son personajes llenos de grandeza) sacrificar la satisfacción del propio gusto, como lo afirma Basilio en su primera gran declaración (acto I, vv. 600 y ss. $^{2}$ ), y como lo demuestra Segismundo al final de sus tribulaciones. En suma, son varios los indicios de que La vida es sueño tiene una trama de tragedia, o, en todo caso, que sitúa a la obra de Calderón entre las de mayor elevación y dignidad, según los tópi-

2 Citaremos La vida es sueño por la ed. de Ruano de la Haza, 1994. 
cos de la definición tradicional y retórica de la tragedia ${ }^{3}$, y los materiales que maneja Calderón para su inventio son los ingredientes habituales de la modalidad trágica.

Calderón, como es muy habitual en el teatro áureo, y, podríamos añadir, en la estética teatral de la edad clásica en Europa, combina esa dimensión fundamental de la trama de La vida es sueño con una historia de amor, una intriga sentimental protagonizada por Rosaura en una serie de escenas en la mayoría de las cuales no participa directamente Segismundo. No hace falta recordar detalladamente las etapas de la historia individual de Rosaura, cuyas apariciones alternan de manera muy rítmica, en cada acto, con las de Segismundo; digamos tan sólo que entre los materiales de que se vale Calderón varios son típicos de la comedia de enredo, que se combinan aquí con motivos que podríamos llamar novelescos, como es el caso para la relación entre Rosaura y su padre Clotaldo, de quien busca el reconocimiento de su paternidad. Si bien el tema amoroso se difumina en el tercer acto, colocado bajo el signo del enfrentamiento militar y de la culminación de la violencia, las escenas en que interviene Rosaura en el segundo acto cuando, disfrazada de criada de Estrella, intenta desbaratar el proyecto de matrimonio entre ésta y Astolfo, recuerdan muchas otras situaciones parecidas en comedias domésticas donde una mujer burlada intenta obstaculizar los planes matrimoniales del galán que la abandonó y que planea casarse con otra mujer; generalmente la dama burlada consigue recuperar al amante inconstante y casarse con él al final, lo que sucede también en La vida es sueño.

${ }^{3}$ Un ejemplo tardomedieval de definición de la tragedia sería el de Íñigo López de Mendoza, Marqués de Santillana, en La Comedieta de Ponza (1444): «Tragedia es aquella que contiene entre sí caídas de grandes reyes e príncipes, así como Hércoles, Príamo e Agamenón, e otros tales, cuyos nacimientos e vidas alegremente se comenzaron e gran tiempo se continuaron, e después tristemente cayeron. E de fablar de estos usó Séneca el mancebo, sobrino de otro Séneca, en las sus tragedias, e Joan Bocacio en el libro De casibus virorum illustrium» (en Sánchez Escribano y Porqueras Mayo, 1972, p. 58). Este tipo de conceptualización sigue vivaz por lo menos bajo la pluma de Lope cuando escribe en la dedicatoria de La campana de Aragón que en la tragedia tenemos «Sucesos, guerras, paces, consejos, diferentes estados de la fortuna, mudanzas, prosperidades, declinaciones de reinos y períodos de imperios y monarquías grandes" (en Décima octava parte de las comedias de Lope de Vega Carpio, 1623, p. 298). 
Aunque Rosaura aparece caracterizada menos como mujer enamorada que como un personaje vengativo, dispuesta a recuperar su honor incluso a costa de la propia vida ${ }^{4}$, y aunque sus intervenciones en el diálogo dramático vienen marcadas por una fuerte carga patética, la crítica tradicional, bajo la influencia del neoclasicismo, ha podido juzgar negativamente esa mezcla de ingredientes de distinta procedencia, que pudo aparecer como una disonancia o una falta de armonía. Menéndez y Pelayo opinaba así que los disfraces, los amoríos de Astolfo con Rosaura, las escenas galantes en torno al episodio del retrato suyo que conserva el gran duque y que ella intenta recuperar (en particular en el acto II, vv. 1724 y ss.), y más generalmente toda la trayectoria de Rosaura, quitan lustre a la acción principal y rompen la unidad tonal de la historia de Segismundo. Para el polígrafo de Santander, Rosaura es un personaje sumido en «una intriga extraña, completamente pegadiza y exótica, que se enreda por todo el drama como una planta parásita ${ }^{5}$. Este juicio y otros del mismo tipo suponen una definición estrecha del subgénero teatral, a partir de los limitados criterios retóricos antes citados, o de un criterio predominantemente temático o tonal, que la crítica posterior ha sabido relativizar, asumiendo que, a la inversa, la mezcla de ingredientes y de tonalidades dispares es característica de la nueva estética de la comedia revolucionada por Lope de Vega en España. Algunos críticos también tienden a hacer de ese dato un rasgo propio de la estética barroca, marcada por la descentralización, frente a la centralidad de un núcleo propia de la estética clasicizante ${ }^{6}$. Monstruo o hermafrodito, según una imagen bien conocida y difundida a principios del XVII para definir el teatro moderno ${ }^{7}$, La vida es sueño presenta pues una acción doble en

${ }^{4}$ Ver el diálogo esticomítico con Clotaldo, que termina con la réplica de éste: «Pues has de perderte, espera, / hija, y perdámonos todos» (La vida es sueño, ed. Ruano de la Haza, p. 287, vv. 2654-2655).

5 Menéndez Pelayo, 1941, p. 29.

6 «La búsqueda de la variedad — frente a la unidad - en la concepción de la obra de arte es, pues, en lo esencial un rasgo de anticlasicismo, común a manieristas y barrocos» (E. Orozco Díaz, Introducción al Barroco, citado por González García, 2008, p. 184 , nota 2$)$.

${ }^{7}$ Ver, por ejemplo, Ricardo del Turia en Apologético de las comedias españolas, quien traduce aquí literalmente Il pastor fido de Guarini: «Ninguna comedia de cuántas se representan en España lo es, sino tragicomedia [...] Cada parte se conserva ella misma como antes era, sin alterarse ni mudarse. [...] Fabuloso Hermafrodito, [...] que 
la cual Rosaura protagoniza una trama amorosa, con elementos de comedia de enredo, y trata de recuperar su honor perdido, mientras que Segismundo protagoniza una trama política y existencial, con la interrogación sobre el poder del albedrío respecto al hado, y con un cuestionamiento más ideológico sobre el recto uso de la potencia política por el monarca.

En realidad existe una fuerte coherencia de las dos tramas, que son interdependientes, lo que significa por consiguiente que el mismo concepto de intriga doble no da correcta cuenta de la estética de Calderón. Esta coherencia de conjunto de las dos tramas ha sido indagada repetidas veces por la crítica desde distintas perspectivas (en particular a partir del trabajo pionero de Wilson, 1946, que insiste en la coherencia temática). Resumiendo mucho, y siguiendo para ello a Diego Marín en un trabajo antiguo que versaba sobre la intriga secundaria en el teatro de Lope ${ }^{8}$, la unidad entre la intriga principal (la de Segismundo) y la secundaria (Rosaura) puede ser orgánica y / o temática. Según una imagen trillada de la doxa neoaristotélica, la coherencia orgánica asemeja la obra de arte a un cuerpo entero compuesto por sus distintas partes (sus distintos miembros $\mathrm{u}$ órganos), las cuales son necesarias, es decir, no solamente ornamentales, para que el mecanismo de la acción funcione correctamente. Cabe entonces diferenciar la unidad de acción, que aparece como un objetivo para el teatro europeo moderno, de la unicidad de la acción, como hace por ejemplo Lope de Vega en conocidos y algo imprecisos versos del Arte nuevo en los que se puede considerar que el Fénix de los Ingenios defiende la duplicidad o la pluralidad de las acciones, si éstas no son meros «episodios» ${ }^{9}$. Por su parte, la coherencia solamente temática no es un defecto, o sería reductor considerarla tal —lo que podría haber sido la opinión de Menéndez y Pelayo - sino que remite sencilla-

de hombre y mujer formaba un tercero participante de la una y la otra naturaleza, de tal manera mixto que no se podía separar la una de la otra» (en Sánchez Escribano y Porqueras Mayo, 1972, pp. 177-178).

8 Marín, 1958.

9 «Adviértase que sólo este sujeto / tenga una acción, mirando que la fábula / de ninguna manera sea episódica, / quiero decir inserta de otras cosas, / que del primero intento se desvíen, / ni que de ella se pueda quitar miembro / que del contexto no derribe el todo" (Lope de Vega, Arte nuevo de hacer comedias en este tiempo, 2006, p. 141, vv. 181-187). 
mente a una estética diferente, que se practica al final del siglo XVI, cuando se trata de renovar el teatro antiguo. Las lecciones de Séneca, por ejemplo, indicaban como vía de perfección estética la coherencia del conjunto en función de ecos, de repeticiones, de inversiones, es decir, en función de relaciones de tipo fundamentalmente analógicas entre las partes.

Las relaciones entre los dos planos de la intriga de La vida es sueño son pues al mismo tiempo analógicas y estructurales. Para la claridad expositiva, podemos tratar separadamente (y sintéticamente) estos dos aspectos, que en realidad van estrechamente unidos. Para lo que hace a la unidad análogica, o temática, Rosaura y Segismundo comparten rasgos comunes que han dado pie a una serie de interpretaciones de tipo más o menos estrictamente psicoanalítico. Llamados por Marc Vitse «mellizos de la desgracia» ${ }^{10}$, ambos personajes son víctimas expoliadas e involucradas en un proceso de recuperación. Rosaura y Segismundo salen en busca de su propia identidad, que tienen que construir a partir de una situación de opresión o de abandono que coincide con su propio nacimiento. Su trayectoria individual corresponde con el acceso gradual y conflictivo a la edad adulta, en un proceso al término del cual consiguen el reconocimiento por el padre, único capaz de asegurar la filiación, según la ideología patriarcal del linaje, banal en el sistema de pensamiento de la época. Este proceso termina con el desenlace matrimonial, cuando Rosaura y Segismundo pueden ocupar el puesto que les corresponde naturalmente en la sociedad, después de su violento enfrentamiento con una figura paterna deficiente, doblemente encarnada en Clotaldo y Segismundo, quienes asumen por fin la autonomía conquistada heroicamente por sus vástagos ${ }^{11}$.

En cuanto a las relaciones estructurales, son seguramente de mayor importancia, sobre todo para la lectura funcionalista que aquí nos

${ }^{10}$ Vitse, 1980, p. 11.

11 Sesé propone en la introducción a su edición bilingüe de La vida es sueño un análisis freudiano de la obra: «Les deux intrigues sont en quelque sorte les répliques parallèles et complémentaires de la même tragédie inconsciente dont La vie est un songe offre la résolution symbolique: la reconnaissance et l'observance de ce que l'on pourrait appeler la Loi du Père, bafouée par Basyle et Clothalde, rétablie par Sigismond, et qui n'est rien d'autre que l'acceptation de la réalité et de ses aléas» (Calderón, La vida es sueño, ed. Sesé, 1992, p. 41). 
ocupa. Quien ha indagado mejor esta profunda coherencia estructural de la acción es quizás de nuevo Vitse ${ }^{12}$, demostrando que los tres encuentros sucesivos (uno en cada acto) de Segismundo con Rosaura — cada vez bajo una apariencia fisica distinta, a pesar de la que, sin embargo, el príncipe logra entender que se encuentra la misma persona que ha conseguido despertar su conciencia de ser humano- le sirven al príncipe para entender, merced a la memoria, que su existencia se inscribe en la duración, en un tiempo dinámico que permite la experiencia por la que se le hace patente que vive en la realidad y no en el sueño; que por lo tanto la vida no es sueño, o solamente lo es en un sentido metafórico (es decir analógico), sino que se parece a un sueño. Convenciéndole en el tercer acto de que salga por segunda vez de la torre, ahora para hacer un uso correcto de su albedrío, es Rosaura quien le proporciona a Segismundo la prueba de la existencia de la realidad y hace posible que el príncipe (y con él, el público) entienda que la fórmula que da su título a la obra es de alcance moral (es necesario actuar bien) y no metafisico (¿existe o no la realidad?) ${ }^{13}$. Cuando Segismundo pronuncia el verso decisivo en que afirma «luego fue verdad, no sueño» (v. 2934), el príncipe sale por fin de la confusión en que Clotaldo le había sumido al final del acto II, a propósito y como parte del plan (o «experiencia», vv. 1077 y 1121) ideado por Basilio. A nivel de la construcción dramática, pues, tanto como en el plano de la construcción del significado axiológico de la obra, el papel de Rosaura es de una importancia fundamental.

\section{El sistema de los personajes}

Ambos personajes se necesitan pues el uno al otro (Segismundo para recuperar su trono, Rosaura para recuperar su honor), y forman parte de un sistema dramático (o sistema de los personajes) cuyo examen ratifica la fuerte interdependencia de sus dos trayectorias individuales y, más allá, la interrelación constante que existe entre los dos galanes (Segismundo y Astolfo) y las dos damas (Rosaura y Estrella) del reparto. Se puede formalizar como sigue este esquema relacional,

${ }^{12}$ Ver en particular Vitse, 1980, pp. 62 y ss.

${ }^{13}$ Ver también el apartado titulado "Structure and theme» de la introducción por Sloman a su edición de La vida es sueño (Caderón, 1961, pp. xiii-xxii). 
que es como una fotografia de las relaciones entre los personajes principales en el desenlace, y que corresponde por lo tanto a los emparejamiento matrimoniales entre los agonistas del drama:
A: Segismundo

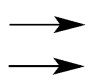
B: Estrella
D: Rosaura
E: Astolfo
C: Astolfo

Este esquema pentagonal (en el que las flechas indican el deseo que empuja a un personaje hacia otro) permite darse cuenta de las interrelaciones entre los dos galanes y las dos damas que se reparten las cinco funciones dramáticas que se suelen encontrar en la comedia de enredo. En la parte superior del cuadro encontramos la pareja formada por Segismundo y su prima Estrella, que realizan una alianza endogámica a expensas de Astolfo, pretendiente forastero (es gran duque de Moscovia, aunque primo de los dos primeros) y vencido tanto en el plano de sus aspiraciones matrimoniales como en el terreno político-dinástico, ya que el bando de Basilio al que se había juntado queda derrotado en su confrontación militar con el príncipe heredero. En el nivel inferior, encontramos la pareja Astolfo-Rosaura, que se forma al término de un arduo proceso de recuperación, por parte de la dama, de quien la había seducido. Aunque Rosaura tiene una importancia dramática mucho mayor que la de Estrella (mero objeto del deseo masculino y sinécdoque de la corona polaca), ésta le es superior socialmente, así como el príncipe Segismundo es de un rango social superior a Astolfo, gran duque de Moscovia; ello explica su presencia en el rango inferior del esquema. Las dos damas no tienen en principio nada que ver, no se relacionan directamente, no pertenecen al mismo espacio geográfico, pero entran en contacto y forman un triángulo amoroso típico de la comedia de enredo cuando Rosaura bajo un disfraz de criada, sirve a Estrella para intentar (sin conseguirlo) impedir la boda concertada entre Astolfo y su prima. Astolfo, por fin, asume una doble función: por una parte, como amante y finalmente marido de Rosaura, asume la función C propia del segundo galán del reparto, el cual siempre se halla en un segundo plano respecto al héroe (aquí Segismundo) y suele intervenir de manera más o menos artificial para que la segunda dama no se quede sin marido; como oponente directo a Segismundo en su intento de casarse con Estrella, ocupa también la función E, propia del tercer galán que ter- 
mina suelto, es decir sin pareja, y cuya exclusión obedece a la justicia poética y / o viene acompañada de una justificación axiológica ${ }^{14}$.

La particularidad de la variante de este esquema funcional, tal como lo utiliza aquí Calderón, es que la doble función de un personaje masculino (C, como segundo galán, y E, como galán suelto y responsable del desorden), o sea la repartición de las cinco funciones entre cuatro protagonistas, es propia de las comedias de (o con) burlador, que suelen terminar con un final feliz aunque muchas de sus situaciones lindan con los subgéneros más graves, en particular porque tocan temas relacionados directamente con el honor. Como veremos ahora, es precisamente lo que ocurre en La vida es sueño, que termina con dos bodas, aunque lo que importa en la constitución de esas parejas es el deber y / o el respeto de las conveniencias sociales, antes que las aspiraciones individuales de los novios. Como si se tratara de una comedia de burlador en la que se hallaría marginada la victoria del eros a favor de la exaltación de una conducta moral y socialmente responsable, el desenlace de La vida es sueño se aleja considerablemente del universo de la comedia cómica en la que los protagonistas realizan transgresiones más o menos graves del decoro para garantizar la victoria del amor.

\section{LA LECTURA HACIA ATRÁS}

Intentaremos ahora encontrar por qué el sistema de los personajes de La vida es sueño, tan cercana en muchos de sus aspectos de la estética trágica, corresponde a una modalidad típica de la comedia de enredo, con un personaje de burlador responsable de una forma de usurpación, pues Astolfo está comprometido con Rosaura y sin embargo pretende casarse con Estrella. Para ello, es necesario prestar atención al desenlace, cuando se anudan definitivamente las dos tramas antes mencionadas, $\mathrm{o}$, desde la otra perspectiva que hemos propuesto, cuando se estabiliza el sistema de los personajes con los dos casamientos que constituyen el verdadero final de la obra, y no son solamente un ornamento convencional. La hipótesis de lectura que proponemos implica, por una parte, que el autor sabe qué tipo de desenlace va a

${ }^{14}$ Sobre el esquema pentagonal, ver Couderc, 2006. 
dar a su obra cuando empieza a escribirla - es decir, sabe si escribe una obra con final feliz o con final funesto-y, por otra parte, que el desenlace hace necesaria la presencia de una trama secundaria, o, en otras palabras, que el poeta construye su intriga a partir del final que tiene presente como una meta a la que la acción debe llevar de manera necesaria ${ }^{15}$. Este acercamiento genético supone pues que remontemos hacia atrás partiendo del desenlace, que existe en la mente del poeta como punto de partida de su proceso de invención, y que podría explicar la presencia de ciertas escenas con una función de relleno. Confrontaremos para ello dos lecturas distintas del desenlace: la primera será cronológica, mientras que la segunda se realizará al revés, a partir del final.

Siguiendo la lectura cronológica, que corresponde a la percepción del espectador que asiste a la representación en el momento fugaz y único en que existe la obra puesta en escena, podemos identificar cuatro etapas sucesivas, que se encadenan en función de lo que dicen y de cómo actúan los personajes. Las dos primeras etapas son dos decisiones que toma Segismundo, cuando declara:

\author{
Pues que ya vencer aguarda \\ mi valor grandes victorias, \\ hoy ha de ser la más alta \\ vencerme a mí. Astolfo dé \\ la mano luego a Rosaura, \\ pues sabe que de su honor \\ es deuda y yo he de cobrarla. (vv. 3255-3261)
}

15 Proponemos aquí una aplicación libre de una herramienta que Forestier, conocido especialista del teatro clásico francés, llama la «lecture à rebours». Partiendo de los análisis del relato desarrollados por Paul Ricoeur en Temps et récit y del concepto (de raigambre aristotélica) de causa final, Forestier estudia unas cuantas piezas de Corneille y de Racine cuya composición, dice, es «regresiva», es decir cuyo elemento fundamental es el desenlace al que tiene que conducir de manera necesaria la serie de acciones que lo preceden: «la tragédie est certes un art de fiction qui, comme tout art narratif, repose sur un enchaînement logique ou probable de causes et d'effets; mais envisagé sur un plan génétique, c'est-à-dire dans la perspective du travail de mise en intrigue, la tragédie classique française se révèle être un genre fondé sur le principe de la cause finale. [...] le dénouement constitue la cause cachée des actions et des discours qui conduisent à lui» (Forestier, 1996, pp. 14-15 y ss.; ver también en su introducción a su edición del teatro de Racine, 1999, pp. XLI y ss.). 
El príncipe empieza por dejar manifiesto su autodominio, el 'vencerse a sí mismo', lugar común en el teatro áureo para alabar la fortaleza y la prudencia del rey, capaz de obedecer a lo justo antes que a su gusto ${ }^{16}$. Es entonces obvio para el espectador que Segismundo renuncia a Rosaura, hacia quien sentía una fuerte atracción, identificada en el texto como pulsión erótica y como amor ${ }^{17}$. La segunda decisión del príncipe, que consiste en obligar a Astolfo a que se case con Rosaura, es consecuencia de la primera, pues Segismundo, en instancias de suceder a su padre en el trono, actúa como un rey justiciero y casamentero, como garante que es del respeto de las obligaciones del honor: la virtud que manifestó en el ámbito privado cuando descartaba el instinto y la pasión a favor de la razón alcanza ahora el ámbito público. Surge entonces un grave escollo, ya que esta obligación contraída por Astolfo («deuda») contraviene a las convenciones sociales, pues Rosaura no conoce a su padre o, como dice el gran duque de Moscovia sin tapujos, «no sabe quién es» (v. 3264).

La sensata observación de Astolfo hace necesaria la anagnórisis (tercera etapa del desenlace), con la intervención de Clotaldo que reconoce públicamente su paternidad, permitiendo que se supere el obstáculo hasta entonces fundamental de la diferencia social entre el duque y la anónima dama, de padre desconocido:

$\begin{array}{ll}\text { Clotaldo } & \text { porque Rosaura es tan noble } \\ \text { como tú, Astolfo, y mi espada } \\ \text { lo defenderá en el campo; } \\ \text { que es mi hija, y esto basta. }\end{array}$

Astolfo ¿Qué dices?

Clotaldo Que yo, hasta verla

casada, noble y honrada,

${ }^{16}$ Con ejemplos sacados del teatro de Lope de Vega, Díez Borque habla del modélico «autodominio del poderoso» y de «la perfección absoluta del rey, que venciéndose a sí mismo en su inclinación amorosa, se retira de la contienda amorosa» (Díez Borque, 1976, pp. 75 y 79).

${ }^{17}$ Ver: «véate yo y muera» en el primer encuentro de Segismundo con Rosaura (v. 233); «solo a una mujer amaba», en el diálogo con Clotaldo al final del acto II, cuando Segismundo ha sido encerrado de nuevo en la torre (v. 2134); «el amor las leyes rompa / del valor», cuando en el acto III está a punto de sucumbir a la tentación de gozarla (vv. 2961-2962). 
no la quise descubrir.

La historia desto es muy larga;

pero, en fin, es hija mía. (vv. 3267-3276)

Puede sorprender la escueta declaración de Clotaldo cuyo sentido literal parece hacer del reconocimiento público de su paternidad una recompensa del mérito de Rosaura, quien ha sabido luchar sola por defender su honor, a no ser que lo interpretemos como si se asumiera el carácter artificial y convencional del procedimiento de la anagnórisis ${ }^{18}$. Sea lo que fuere, llega la cuarta y última fase del desenlace, es decir el casamiento de Segismundo y Estrella:

Segismundo Pues, porque Estrella no quede desconsolada, viendo que príncipe pierde de tanto valor y fama, de mi propia mano, yo con esposo he de casarla que, en méritos y fortuna, si no le excede le iguala.

Dame la mano. (vv. 3178-3286)

A esta lectura cronológica del desenlace, que empieza con la renuncia del príncipe y termina con una boda compensatoria para Estrella, nos invita el propio Segismundo, asumiendo su papel de monarca que dispone, ordena, toma decisiones, a las que la realidad se amolda, dándonos la sensación de ser un personaje clarividente y voluntarioso, y ya no una víctima pasiva de una suerte que le ha sido impuesta. Por otra parte, en cuanto a las estructuras dramáticas, esta lectura que podríamos llamar superficial (y que nos proponemos matizar a continuación) es conforme con la lógica propia de la comedia

18 En realidad es este punto también Calderón juega con las convenciones. Clotaldo se ahorra, y ahorra al público, la «historia muy larga» cuyo relato suele intervenir en este tipo de situaciones en el teatro o la novela, con algún personaje que, como el nuncio del teatro antiguo, es portador de informaciones hasta entonces desconocidas. Quizás preocupado por la verosimilitud, o con la voluntad de renovar los tópicos, Calderón elabora una intriga al término de la cual no cabe duda ni para Rosaura, ni para Clotaldo ni, sobre todo, para el espectador, de la identidad de la dama. Por consiguiente es totalmente inútil el relato de esta «historia». 
de enredo, haciendo del matrimonio de Segismundo con Estrella una consecuencia relativamente imprevista de una historia de amor, de celos, de seducción nocturna, y de una conducta poco decorosa tanto de Astolfo como de Rosaura. En estas condiciones, la venganza de honor y el asunto privado que nutren la intriga secundaria primarían sobre la reconquista del poder y el asunto público. A la inversa, el casamiento del príncipe con Estrella, que garantiza la inscripción del linaje de Basilio en el tiempo, se subordinaría a la intriga amorosa, aparecería como contingente y solamente como un casamiento compensador para Estrella, porque ha perdido a Astolfo, y para Segismundo, porque renuncia a Rosaura.

Podemos por lo tanto intentar leer el desenlace de una forma algo distinta, organizando los mismos datos a partir del final, es decir a partir del casamiento de Segismundo con su prima hermana Estrella, a partir de la hipótesis verosímil según la cual Calderón se plantea muy temprano cuando escribe La vida es sueño que el final será este, y no otro. Primero porque el matrimonio es una convención de los finales felices. Luego porque es necesario que se case el príncipe en el sentido de que ello es símbolo de su acceso a la edad adulta, cuando se termina su confrontación con su padre, quien le da de nuevo la vida ${ }^{19}$. Por fin porque se realiza de esta forma una unión matrimonial endogámica entre el príncipe y su prima, acorde con los deseos expresados por el pueblo, favorable al respeto del derecho natural. El matrimonio final de Segismundo con Estrella tiene en efecto un carácter político coherente con lo que precede en la acción: ya en el primer acto, cuando la corte de Polonia se entera de la existencia de Segismundo, el personaje colectivo llamado «todos» le contesta a Basilio «¡Danos al príncipe nuestro, / que ya por rey le pedimos!» (vv. 850851). Luego, al principio del acto tercero, el soldado que saca a Segismundo de su torre se encarga de justificar muy explícitamente la rebelión popular porque Basilio se dispone a transmitir su corona a Estrella y Astolfo, rey consorte y extranjero, a expensas del heredero natural de la corona polaca ${ }^{20}$. Matrimonio endogámico, cerrazón del grupo social sobre sí mismo, y preferencia por lo local son caracterís-

${ }^{19}$ Ver los vv. 3248-3250 pronunciados por Basilio: «Hijo, que tan noble acción / Otra vez en mis entrañas / te engendra [...]».

${ }^{20}$ Ver vv. 2276-2305. 
ticas que se encuentran en no pocos desenlaces de tragedias, de comedias palatinas y, más generalmente, de comedias que podríamos llamar graves o serias ${ }^{21}$.

Consideremos por consiguiente que el casamiento con el que Segismundo debe coronar su trayectoria victoriosa es el fundamento de la invención, su punto de partida, al que la intriga tiene necesariamente que llevar. Por otra parte, dada la estética teatral a la que responde La vida es sueño, también es necesario que la acción se desarrolle como un conflicto que toma la forma de una rivalidad entre distintos galanes para la mano de una dama ${ }^{22}$. Para que las fuerzas estén equilibradas en el conflicto, el competidor con quien se enfrenta el príncipe polaco debe ser del mismo rango que él: ése es Astolfo, su primo hermano, gran duque de Moscovia e hijo de una hermana menor del rey Basilio casada fuera del país. De este enfrentamiento, Astolfo sale vencido. Pero sería un desdoro excesivo para él terminar en posición de galán suelto, y es por lo tanto para Astolfo (y no para Segismundo, héroe y vencedor) como habría que considerar que el enlace matrimonial (con Rosaura) es un casamiento de compensación. De ahí que sea necesario (siempre si nos remontamos hacia atrás), el personaje de Rosaura, que sale en busca de Astolfo hasta Polonia, lo que justifica sus relaciones con Segismundo, la importancia de sus encuentros, así como las múltiples reticencias de Clotaldo para reconocer públicamente que Rosaura es su hija.

A esto se puede añadir para terminar la consideración de las variaciones entre la primera y la segunda versión de La vida es sueño, convenientemente estudiadas por José Maria Ruano de la Haza. La primera redacción (probablemente la que hizo Calderón para los corrales antes de pulirla para los lectores), presenta a un Segismundo algo distinto, en el sentido de que manifiesta una buena dosis de cinismo,

${ }^{21}$ Ver Couderc, 2010.

22 La competición es política, aunque se expresa con el lenguaje de la rivalidad amorosa: ya en el primer encuentro entre Astolfo y Segismundo (inicio del acto II), cuando el príncipe se dirige con una alambicada metáfora a Estrella y le pide su mano a besar, Astolfo comenta en un aparte, jugando con el sentido literal y el figurado del enunciado: "si él toma la mano, soy perdido» (vv. 1408-1409). Es entonces cuando el criado que asiste a la escena se entremete, comentando «el pesar sé / de Astolfo, y le estorbaré» (vv. 1409-1410), suscitando a continuación la ira de Segismundo que le arroja por el balcón. 
como apunta Ruano de la Haza. Las variaciones afectan sutilmente al personaje de Segismundo (siempre parafraseando a Ruano), notablemente en el acto tercero, donde los versos modificados indicaban como primer motivo para renunciar a Rosaura la repulsa hacia una mujer que ya perteneció a otro e inhabilitada por lo tanto para casarse con un futuro rey:

\author{
$[\ldots]$ baxa cosa \\ debe de ser en el mundo, \\ en materias amorosas, \\ amar lo que otro olvida, \\ o querer lo que otro goza. (vv. 2980-2981)
}

Lo que llama Ruano "grosera declaración de Segismundo", eliminada a favor de su «ennoblecimiento» en la segunda versión ${ }^{23}$, podría verse como un ligero fallo en la construcción de la acción, sobre todo si se considera (lo que se puede discutir) que el final de la obra debía acompañarse de un mensaje ético merced a la presentación de Segismundo como príncipe modélico capaz de vencerse a sí mismo ${ }^{24}$. Lo indiscutible es que Calderón prefiere modificar el texto para elaborar un desenlace en que más bruscamente el príncipe da un giro en su conducta y parece elegir entre dos opciones, es decir hacer un recto uso de su albedrío, a favor de la virtud. Reconocer antes del momento final que existía una imposibilidad para casarse con Rosaura o que la repulsa hacia ella era tan fuerte que Segismundo renunciaba siquiera a gozarla impedía en la primera versión que se mantuviera cierta dosis de suspense cuando llega el momento de los emparejamientos matrimoniales. En la primera versión, se anunciaba demasiado temprano cuál era la función final reservada a Rosaura, es decir la de pareja de sustitución para que no se quedara suelto Astolfo después de haber sido un objeto de tentación para Segismundo. Cuando llegaba la última escena, el espectador podía haberse dado cuenta de que en realidad no podía prosperar una relación entre Rosaura y Segismundo, y de que, por lo tanto, menos que de renuncia se trataba de acomodarse con pragmatismo a la realidad de la situación.

23 Ruano de la Haza, 1992, p. 87.

24 Campbell comenta también estos versos: «su rechazo total, su disgusto, restan fuerza a su conversión final: el vencimiento de sí mismo» (2008, p. 74). 
Para resumir, digamos que el príncipe debe casarse con su prima, lo que implica que su rival Astolfo se quede solo, y necesite una compensación. El matrimonio final es el principal, y es necesario para rematar una acción de alto contenido político, pues con este enlace de Segismundo con Estrella se asegura la continuidad del linaje polaco. La misma lógica política impide que Astolfo, casándose con Estrella, ponga en peligro la estabilidad del reino, pues Estrella tiene derechos a la sucesión del reino de Polonia. Pero, dada la categoría social de Astolfo, no puede quedarse suelto, y para subsanar este rebajamiento surge Rosaura; es decir, ha surgido desde el inicio, y sólo al final cumple con su función tal vez prevista de entrada por el dramaturgo, es decir, que pueda servir de contrapeso al matrimonio político de Segismundo con Estrella. Aunque contraria a la cronología del discurso, esta lectura es más satisfactoria que la primera: porque Segismundo debe casarse con su prima y asimismo apartarse de sus instintos, esto es, vencerse a sí mismo, es por lo que Astolfo es caracterizado como galán burlador. Si se acepta que el matrimonio de Segismundo con Estrella es la meta hacia la que se orienta la acción, entonces es una necesidad de tipo estructural la que justifica la presencia de una historia de dama burlada en un drama serio, político y moral. 


\section{Bibliografía}

ArA, J. A., «Estructuras iterativas en La vida es sueño», Criticón, 45, 1989, pp. 95-112.

Calderón de la Barca, P., La vida es sueño, ed. A. E. Sloman, Manchester, Manchester University Press, 1961.

- La vida es sueño, édition, introduction, traduction et notes B. Sesé, Paris, GF-Flammarion, 1992.

- La vida es sueño, ed. J. M. Ruano de la Haza, Madrid, Castalia, 1994.

Campbell, Y., "Las versiones de Zaragoza y Madrid de La vida es sueño: continuidad y ruptura», Anuario calderoniano, 1, 2008, pp. 67-85.

Couderc, C., Galanes y damas en la Comedia Nueva. Una lectura funcionalista del teatro español del Siglo de Oro, Madrid / Frankfurt, Iberoamericana / Vervuert, 2006.

- «Estrategias matrimoniales y reproducción social en la comedia palatina de Mira de Amescua», en Cuatro triunfos áureos y otros dramaturgos del Siglo de Oro, ed. A. González, S. González y L. von der Walde Moheno, México, El Colegio de México / Universidad Autónoma de México / AITENSO, 2010, pp. 105-133.

Díez Borque, J. M. ${ }^{\text {, }}$, Sociología de la comedia española del siglo XVII, Madrid, Cátedra, 1976.

Forestier, G., Essai de génétique théâtrale. Corneille à l'ceuvre, Paris, Klincksieck, 1996.

GonzÁlez García, S., "La trama secundaria de Casa con dos puertas mala es de guardan,, Anuario Calderoniano, 1, 2008, pp. 183-199.

Halkhoree, P., "A Note on the ending of Calderón's La vida es sueño», Bulletin of the Comediantes, 24, 1972, pp. 8-11.

Marín, D., La intriga secundaria en el teatro de Lope de Vega, Toronto, University of Toronto Press, 1958.

Menéndez Pelayo, M., Calderón y su teatro, en Estudios y discursos de crítica literaria, Madrid, CSIC, 1941, vol. III.

Racine, J., Euvres complètes, vol. I (Théâtre et poésies), Paris, Gallimard, Bibliothèque de la Pléiade, 1999.

Ruano de la Haza, J. M. , La primera versión de "La vida es sueño» de Calderón, Liverpool, Liverpool University Press, 1992.

Sánchez Escribano, F. y Porqueras Mayo, A., Preceptiva dramática del Renacimiento y el Barroco, Madrid, Gredos, 1972.

Sloman, A. E., "The Structure of La vida es sueño», Modern Language Review, 48, 1953, pp. 293-300.

Vega, L. de, Arte nuevo de hacer comedias en este tiempo, ed. E. García SantoTomás, Madrid, Cátedra, 2006. 
- Décima octava parte de las comedias de Lope de Vega Carpio, Madrid, Juan González, 1623.

Vitse, M., Segismundo et Serafina, Toulouse, France-Ibérie Recherche, 1980. Whitвy, W. M., "Rosaura's role in the structure of La vida es sueño», Hispanic Review, 28, 1960, pp. 16-27.

Wilson, E. M., "La vida es sueño», Revista de la Universidad de Buenos Aires, 4, 1946, pp. 61-78. 